\title{
Mudança do Uso e da Cobertura da Terra e Hemerobia das Paisagens: o caso da Região Geográfica Imediata de Belém - Pará (1985-2018)
}

\author{
Land Use and Land Cover Change and Landscape Hemeroby: the case of the \\ Immediate Geographic Region of Belém - Pará (1985-2018)
}

\section{Cambio de Uso y Cobertura del Suelo y Hemerobia de las Paisajes: el caso de la Región Geográfica Inmediata de Belém - Pará (1985-2018)}

\author{
Luiz Henrique Almeida Gusmão ${ }^{1}$ \\ https://orcid.org/0000-0003-1801-1464 \\ Marco Aurélio Arbage Lobo² \\ https://orcid.org/0000-0002-3366-4992 \\ Helena Lúcia Zagury Tourinho ${ }^{3}$ \\ https://orcid.org/0000-0001-7588-1680
}

\begin{abstract}
RESUMO: As atividades humanas têm alterado padrões e processos ecológicos ao longo do tempo. Diversos indicadores buscam mensurar as transformações antrópicas nas paisagens, dentre eles o índice de hemerobia, conceito que define a intensidade das alterações na estrutura e função da paisagem decorrentes das atividades humanas. Este estudo, usando informações sobre uso e cobertura da terra da Região Geográfica Imediata de Belém/PA, quantificou, categorizou e analisou os graus de hemerobia dos 15 municípios dessa região. Para calcular e representar classes de uso do solo e índices hemerobióticos, usaram-se dados do Projeto MapBiomas para 1985 e 2018 e um software de geoprocessamento para confeccionar mapas temáticos. O estudo evidenciou os limites e possibilidades do índice de hemerobia contribuir para os estudos regionais, ao graduar os níveis de impactos ambientais das várias classes de usos do solo. Adicionalmente, mostrou que a região de estudo: foi moderadamente impactada pelas atividades humanas; as pastagens são as principais modificadoras da paisagem; as áreas florestais predominam na maioria dos municípios apesar das sucessivas expansões de áreas urbanizadas e de pastagens; a maioria dos municípios possui moderado grau de intervenção humana nas suas paisagens e as classes de maior transformação da paisagem são pouco expressivas na região.
\end{abstract}

\footnotetext{
${ }^{1}$ Mestrando em Desenvolvimento e Meio Ambiente Urbano (UNAMA). E-mail: henrique.ufpa@hotmail.com.

${ }^{2}$ Doutor em Desenvolvimento Socioambiental (UFPA). Professor e pesquisador do Programa de Pós-Graduação em Desenvolvimento e Meio Ambiente Urbano, Universidade da Amazônia (UNAMA). E-mail: lobo2502@gmail.com.

${ }^{3}$ Doutora em Desenvolvimento Urbano (UFPE). Professora e pesquisadora do Programa de Pós-Graduação em Desenvolvimento e Meio Ambiente Urbano, Universidade da Amazônia (UNAMA). E-mail: helenazt@uol.com.br.
} 
PALAVRAS-CHAVE: Planejamento da paisagem. Geoecologia. Hemerobia.

\begin{abstract}
Human activities have changed ecological patterns and process overtime. Several statistics seek to measure anthropogenic changes in landscapes, including the hemeroby index, concept that defines the intensity of changes in the structure and function of landscapes resulting from human activities. This study, using information on land use and land cover in the Immediate Geographic Region of Belem (Brazil), quantified, categorized, and analyzed the hemeroby degrees in the 15 municipalities of that region. To calculate and represent land use classes and hemeroby indices, MapBiomas Project data of 1985 and 2018 were used and a geoprocessing software to make thematic maps. The study showed the limits and possibilities of the hemerobia index to contribute to regional studies, by grading the levels of environmental impacts of the various of land uses classes. Additionally, it showed that the study region: was moderately impacted by human activities; pastures are the main modifiers of the landscape; forest areas predominate in most municipalities despite successive expansions of urbanized areas and pastures; most of the municipalities have a moderate degree of human intervention in their landscapes and the classes that promote more severe transformation in the landscape are not very significant in the region.
\end{abstract}

KEYWORDS: Landscape planning. Geo-ecology. Hemeroby.

RESUMEN: Las actividades humanas han cambiado los patrones y procesos ecológicos. Varios indicadores buscan medir los cambios antropogénicos en paisajes, incluido el índice de hemerobia, concepto que define la intensidad de esos cambios en la estructura y función del paisaje. Este estudio, utilizando información sobre uso y cobertura del suelo en la Región Geográfica Inmediata de Belém (Brasil), cuantificó, categorizó y analizó los grados de hemerobia en esa región. Para calcular y representar las clases de uso de la tierra y los índices hemerobióticos, se utilizaron datos del Proyecto MapBiomas para 1985 y 2018 y software de geoprocesamiento para hacer mapas temáticos. El estudio mostró los límites y posibilidades del índice de hemerobia para contribuir a los estudios regionales, al calificar los niveles de impactos ambientales de las diversas clases de uso de la tierra. Además, mostró que la región de estudio: fue moderadamente impactada por las actividades humanas; los pastos son los principales modificadores del paisaje; las áreas forestales predominan en la región a pesar de sucesivas expansiones de áreas urbanizadas y pastos; predomina en la región un grado moderado de intervención humana en sus paisajes y las clases de mayor transformación del paisaje son poco significativas.

PALABRAS-CLAVE: Planificación del paisaje. Geoecología. Hemerobia.

\title{
INTRODUÇÃO
}

As atividades antropogênicas têm alterado, significativamente, os padrões e os processos ecológicos ao longo dos séculos. Essas modificações têm contribuído para a expansão de cidades, lavouras, pastagens e outros usos da terra em detrimento do ambiente natural. Na literatura científica há diversas abordagens teórico-metodológicas destinadas a mensurar as transformações antrópicas nas paisagens, dentre elas está a hemerobia.

O termo hemerobia é oriundo do grego: hémeros (cultivado ou domesticado) e bíos (vida) (STEINHARDT et al., 1999; WALZ e STEIN, 2014; BERTO, 2019). No âmbito da 
análise dos estudos ambientais, o conceito de hemerobia foi concebido pelo professor e botânico finlandês Arvo Jaako Jalas, em 1955, para mensurar o impacto humano na flora e na fauna (WALZ e STEIN, 2014; BERTO, 2019). A abordagem de Jalas para avaliar a interferência humana instituiu quatro graus hemerobióticos, da condição mais preservada à mais antropizada, denominados: a-hemerobiótico, oligo-hemerobiótico, meso-hemerobiótico e eu-hemerobiótico (BELÉM e NUCCI, 2011; WALZ e STEIN, 2014; BERTO, 2019).

Na década de 1970, a noção de hemerobia foi estendida para todos os ecossistemas, conforme proposto pelo botânico alemão Herbert Sukopp (WALZ e STEIN, 2014). Para Belém e Nucci (2011), todos os impactos das atividades humanas, diretos e indiretos, eram concebidos como formas de intervenção nos ecossistemas e paisagens que poderiam ser mensurados pela hemerobia. Tal proposta tem aplicação mais ampla, em extensão geográfica, e é distinta da apresentada por Arvo Jalas.

Hoje, há duas principais perspectivas sobre o conceito de hemerobia. A primeira refere-se à intensidade das transformações antrópicas na paisagem - mais recorrente entre os autores -, e a segunda diz respeito ao grau de dependência energética e tecnológica para manutenção das paisagens (BELÉM e NUCCI, 2011; BERTO, 2019). Na abordagem mais usada, a hemerobia é concebida como a medida de todas as mudanças ocorridas na estrutura e no funcionamento da paisagem em decorrência da ação humana (MATEO RODRIGUEZ, SILVA e CAVALCANTI, 2017), sendo expressa por classes de uso do solo. Por conseguinte, a hemerobia mensura a distância entre uma paisagem predominantemente natural - pouco transformada - e outra intensamente modificada pela ação antrópica.

Os graus de hemerobia destacam as intensidades dos impactos humanos na paisagem (WALZ e STEIN, 2014). Quanto maior o grau de hemerobia, maiores serão os efeitos adversos de forma integrada nos componentes naturais, tais como cobertura vegetal, mundo animal, composição da atmosfera, microrrelevo, microclima, solos, águas superficiais, águas subterrâneas, estrutura geológica, mesorrelevo e mesoclima (MATEO RODRIGUEZ, SILVA e CAVALCANTI, 2017). Desse modo, a hemerobia é um conceito que pode ser utilizado com o intuito de monitorar as mudanças ambientais realizadas pelo homem na paisagem (NUCCI e FÁVERO, 2003; BELÉM e NUCCI, 2011; WALZ e STEIN, 2014).

Por paisagem, entende-se a porção do espaço constituída por elementos físicos, biológicos e antrópicos, cuja configuração resulta da combinação dinâmica desses elementos, formando um conjunto único e indissociável (BERTRAND, 2004). Na concepção de diversos autores, cada tipo de uso do solo reflete de forma diferente as mudanças na dinâmica e na estrutura da paisagem, o que torna possível adotar a hemerobia como métrica dessas conversões. Entende-se que todas as paisagens são, direta ou indiretamente, impactadas pelo ser humano. Contudo, a inserção de alguns tipos de uso do 
solo altera de forma mais acentuada a dinâmica e a estrutura natural, como a urbanização e as atividades agrícolas ou pastoris. Outras modificam de modo menos perceptível, a exemplo da implantação de unidades de preservação ambiental ou de áreas naturais com uso recreativo.

Entre os projetos que monitoram e mapeiam o uso e a cobertura da terra do território brasileiro, destaca-se o MapBiomas. Essa rede interinstitucional dividiu o Brasil em classes de cobertura natural (formação florestal, formação savânica, formação campestre, mangue, formação natural não florestal, água, apicum, praias e dunas, entre outras) e classes de uso antrópico (floresta plantada, agricultura, pastagens, outras áreas não vegetadas, mineração, infraestrutura urbana e outros) conforme as especificidades geográficas (MAPBIOMAS, 2020a).

Considerando que a hemerobia é uma abordagem que possibilita identificar e mensurar as mudanças drásticas que resultam na transformação de um ambiente predominantemente natural até outro intensamente alterado pelo ser humano, e utilizando os dados da plataforma MapBiomas, o presente artigo procura avaliar a hemerobia da paisagem a partir das alterações no uso e cobertura da terra dos municípios da Região Geográfica Imediata de Belém, localizada no estado do Pará, entre o ano de 1985 e 2018.

\section{LOCALIZAÇÃo E CARACTERIZAÇÃo DA REGIÃo GEOGRÁFICA IMEDIATA DE BELÉM/PA}

A área de estudo (Figura 1), localizada na porção nordeste do Estado do Pará, Brasil, está inserida na Amazônia brasileira. É formada por 15 municípios totalizando 17.462,6 quilômetros quadrados (MAPBIOMAS, 2020b).

Conforme estimativa do Instituto Brasileiro de Geografia e Estatística, viviam cerca de 2,7 milhões de habitantes no ano de 2020 (IBGE, 2020a). Ressalte-se que na área de estudo está Belém, a capital paraense, e mais cinco dos sete municípios que compõem a Região Metropolitana de Belém, Ananindeua, Marituba, Benevides, Santa Bárbara do Pará e Santa Izabel do Pará). 
Figura 1 - Municípios da Região Geográfica Imediata de Belém/PA

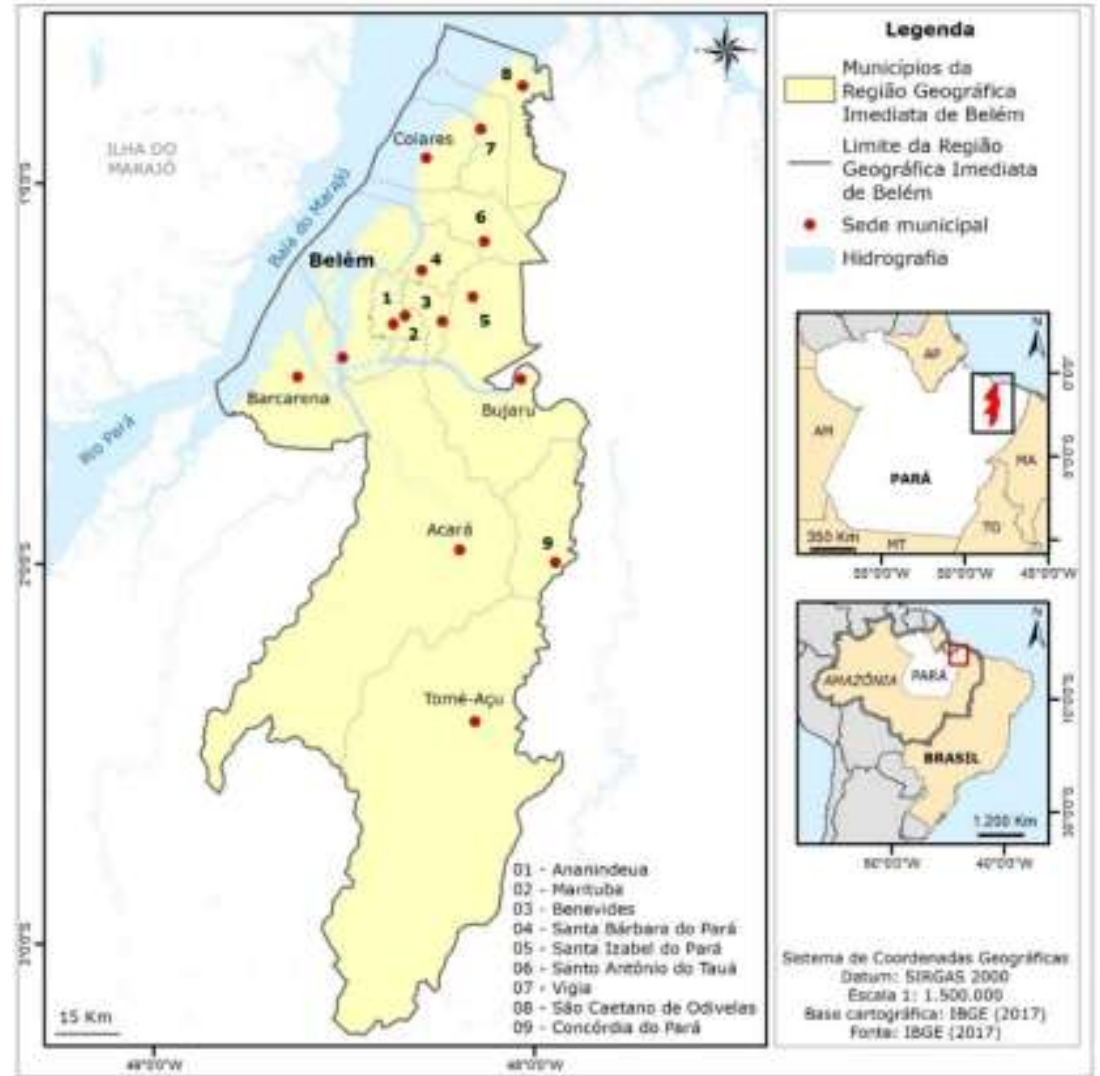

Fonte: IBGE (2017).

\section{METODOLOGIA}

A metodologia adotada procurou, de um lado, contextualizar a área de estudo e suas transformações antrópicas decorrentes da intensificação da agropecuária e do processo de urbanização e, de outro lado, aplicar a abordagem da hemerobia para dimensionar tais mudanças. No que tange à análise da hemerobia propriamente dita, adotou-se a classificação da hemerobia proposta por Walz e Stein (2014), porém com adaptações; e os dados de uso e cobertura da terra para os anos de 1985 e 2018, disponíveis na plataforma digital da Coleção 4.1 do Projeto MapBiomas (MAPBIOMAS, 2020a).

Para a construção da base cartográfica da área de estudo usada no item referente à hemerobia, inicialmente foi realizado o download, em formato shapefile, das Regiões Geográficas Imediatas do Brasil no site do IBGE - Instituto Brasileiro de Geografia e Estatística (2020b) e dos municípios brasileiros. Em seguida, com o uso de software de geoprocessamento, as bases dos municípios que compõem a Região Geográfica Imediata de Belém/PA foram exportadas em formato shapefile. Na sequência, os arquivos em formato raster referentes ao uso e cobertura da terra, para os anos de 1985 e 2018, foram obtidos no site do Mapbiomas (MAPBIOMAS, 2020b) e carregados no software QGIS, mediante o uso das ferramentas "Extrair" e "Recortar raster pela camada de máscara". 
As estatísticas das classes de uso e cobertura da terra, em formato $x / s$, da área de estudo também foram coletadas no site do Projeto Mapbiomas (MAPBIOMAS, 2020b). Com o uso do software Excel procedeu-se os cálculos dos percentuais de cada tipo de uso e cobertura da terra em relação à área total do município, assim como dos índices hemerobióticos para cada ano de análise. Também foi quantificada a variação percentual do índice hemerobiótico e efetuado o enquadramento de impacto humano na paisagem, conforme os intervalos (entre 1 e 7) propostos por Walz e Stein (2014) (Figura 2).

Figura 2 - Cálculos do índice hemerobiótico e da variação percentual da hemerobia (A) e intervalos para avaliação geral do impacto humano na paisagem (B)

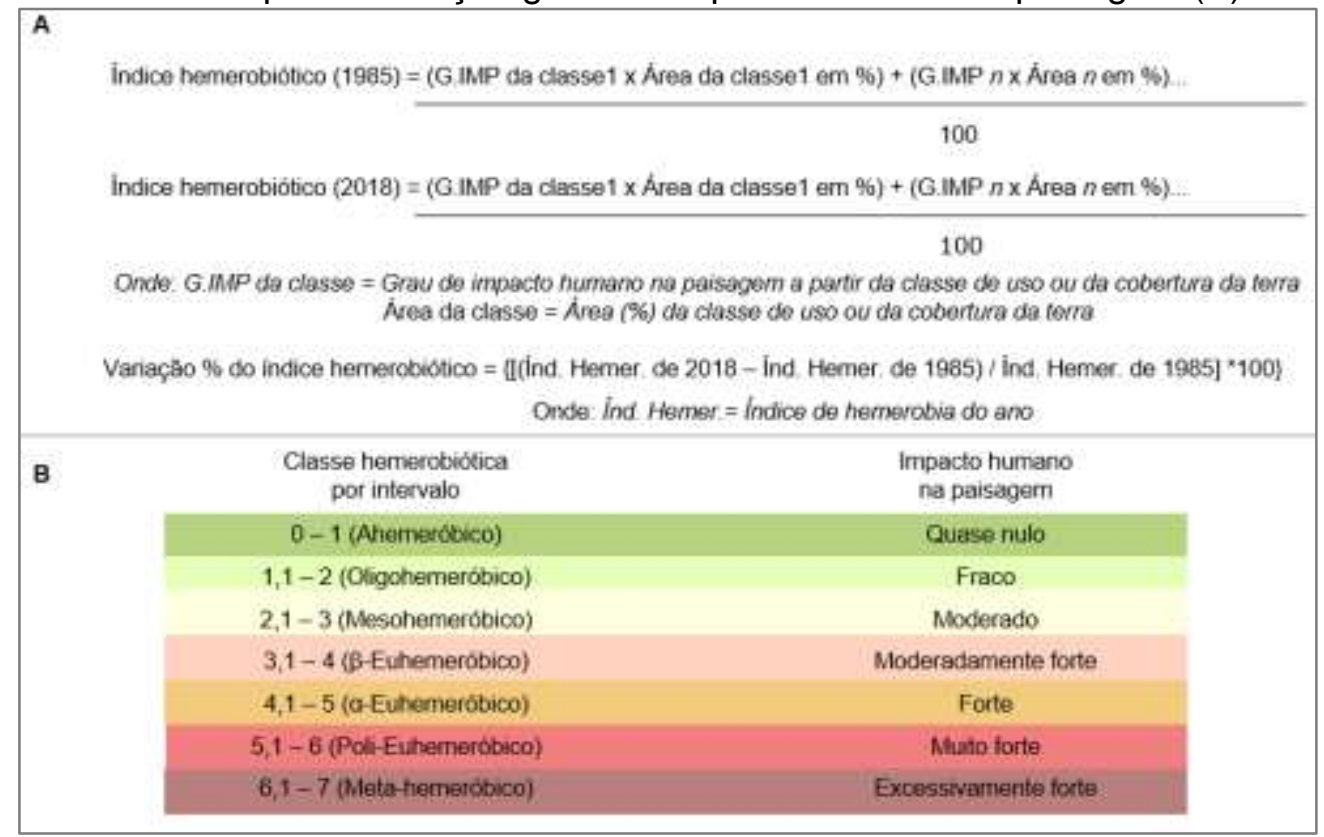

Fonte: Walz e Stein (2014) e Steinhardt et al. (1999).

A partir da escala adotada, quanto mais próximo de 1, menores as mudanças na estrutura e no funcionamento da paisagem pelas atividades antrópicas. De forma contrária, quanto mais próximo de 7 , mais profundas as alterações realizadas na paisagem. Os índices de hemerobia da área de estudo de cada ano foram dimensionados com base no grau de impacto do uso ou da cobertura da terra em relação a extensão territorial. Para isso adotou-se a proposta de classificação da hemerobia de Walz e Stein (2014) exposta na Figura 3, assim como uma adaptação dos tipos de uso e cobertura da terra de acordo com as classes presentes do MapBiomas para área de estudo.

A classe áreas predominantemente natural agrupa todas as coberturas da terra presentes na área de estudo: formação florestal, apicum, praias e dunas, mangues e outras formações naturais não florestais, conforme os dados do Mapbiomas. Já os mapas de hemerobia para área de estudo foram confeccionados no software QGIS 2.18. Os métodos cartográficos adotados foram os propostos por Martinelli (2011) sendo que o coroplético 
representou, com cores ordenadas, a intensidade das modificações realizadas pelas atividades antrópicas na paisagem; e o corocromático destacou, com cores discrepantes, os usos e coberturas da terra de modo individual.

Figura 3 - Classificação hemerobiótica de Walz e Stein para a Alemanha (A) e adaptação da classificação para área de estudo com classes do Projeto MapBiomas (B)

\begin{tabular}{|c|c|c|c|}
\hline A) $\begin{array}{c}\text { Classe } \\
\text { hemerobiótica }\end{array}$ & Classe de uso e cobertura da terra & Impacto humano & $\begin{array}{l}\text { Grau de } \\
\text { impacto }\end{array}$ \\
\hline Ahemerobico & Rochas, geleiras e neve perpétua & QUASE NULO & 1 \\
\hline Oligokiemeróbico & $\begin{array}{l}\text { Forestas, praias, dunas, areias, } \\
\text { päntanos, turfeiras, zonas úmindas, lagoas } \\
\text { costeiras, estudianos, mares e oceanos. }\end{array}$ & FRACO & 2 \\
\hline Mesohemeróbico & $\begin{array}{l}\text { Pastagens naturais, arbusto florestal de } \\
\text { transiç̧o, áreas queimadas, dreas com } \\
\text { vegetaçso escassa, etc. }\end{array}$ & MODERADO & 3 \\
\hline B-Euhemeróbico & $\begin{array}{l}\text { Áreas verdes urbanas, pastagens, ḋreas } \\
\text { agricolas, cursos d’ ojgua e massas } d^{\prime} \text { agua. }\end{array}$ & $\begin{array}{l}\text { MODERADAMENTE } \\
\text { FORTE }\end{array}$ & 4 \\
\hline a-Euhemeróbico & $\begin{array}{l}\text { Instalacles de esporte e lazer, terra arível } \\
\text { năb-irngada, vinhedos, árvores frutiferas e } \\
\text { padröes complexos de cultivo. }\end{array}$ & FORTE & 5 \\
\hline Poli-Euhemeróbico & $\begin{array}{l}\text { Tecido urbano descontinuo, canteiros } \\
\text { de obras e, locass püblicos e industriais } \\
\text { de despejo de minas. }\end{array}$ & $\begin{array}{l}\text { MUTIO } \\
\text { FORTE }\end{array}$ & 6 \\
\hline Meta-hemerobico & $\begin{array}{l}\text { Tecido urbano continuo, unidades } \\
\text { industrials ou cornercials, rodovia, } \\
\text { ferrovia e servicos associados, portos e aeroportcs. }\end{array}$ & $\begin{array}{l}\text { EXCESSIVAMENTE } \\
\text { FORTE }\end{array}$ & 7 \\
\hline B) $\begin{array}{c}\text { Classe } \\
\text { hemerobiótica }\end{array}$ & Classe de uso ou cobertura da terra & Impacto humano & $\begin{array}{l}\text { Grau de } \\
\text { impacto }\end{array}$ \\
\hline Ahemeróbico & - & QUASE NULO & $\mathbf{1}$ \\
\hline Obgohemerobico & 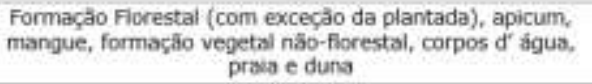 & FRACO & 2 \\
\hline Mesohemerobico & $\begin{array}{l}\text { Pastagem, Floresta plantada e Mosaico de agricultura e } \\
\text { pastagem }\end{array}$ & MODERADO & 3 \\
\hline B-Euhemeróbico & Agricultura (Cultura semi-perene) & $\begin{array}{l}\text { MODERADAMENTE } \\
\text { FORTE }\end{array}$ & 4 \\
\hline a-Euhemerobico & Agricultura (Cultura anual e perene) & FORTE & 5 \\
\hline Poll-Euhemeróbico & Mineraçằo. & MUITO FORTE & 6 \\
\hline Meta-hemerobico & $\begin{array}{l}\text { Infraestrutura Urbana e Cutras áreas nào } \\
\text { vegetadas }\end{array}$ & $\begin{array}{l}\text { EXCESSIVAMENTE } \\
\text { FORTE }\end{array}$ & 7 \\
\hline
\end{tabular}

Fonte: Walz e Stein (2014) e MapBiomas (2020a).

\section{FUNDAMENTAÇÃO TEÓRICA}

A expansão urbana é um dos processos que provoca maior alteração da paisagem natural devido à perda quase completa que promove nos componentes hídricos, faunísticos, florísticos etc. (MOTTER, 2011; MATEO RODRIGUEZ, SILVA e CAVALCANTI, 2017). Elementos naturais como atmosfera, vegetação, fauna, relevo, águas superficiais e subterrâneas, solos e geologia estão dentre os mais impactados nas áreas urbanizadas (MATEO RODRIGUEZ, SILVA e CAVALCANTI, 2017). Assim, como realçam Walz e Stein (2014), a urbanização tem um poder excessivamente forte de alterar a paisagem e de modificar, drasticamente a dinâmica natural.

Entre os principais impactos associados ao processo de urbanização destacam-se: geração de ruídos, emissão de poluentes atmosféricos, aumento de demanda de água, impermeabilização do solo, aumento do escoamento superficial, degradação da flora e da 
fauna, desflorestamento, mudança substancial na estrutura do solo, geração de materiais particulados, dispersão de resíduos e esgotos nas vias públicas etc. (JUCHEM, 1993).

Ademais, o aumento populacional associado com a demanda por habitação, emprego, educação e lazer requerem sistemas de circulação mais complexos. Assim, malhas viárias, portos e aeroportos são construídos para propiciar a movimentação de pessoas e mercadorias. Os principais efeitos ao meio ambiente provocados por esses sistemas são, entre outros: a degradação de ecossistemas frágeis; a alteração do uso da terra, das condições hidrológicas e hidrogeológicas; a interferência na circulação de animais silvestres e selvagens; a geração de ruídos, fuligem e gases; a ocorrência de queimadas acidentais; o aumento da caça e da pesca ilegal; a degradação visual; a redução da qualidade do ar; a emissão de poluentes e materiais particulados; e o derramamento de óleos e graxas das embarcações.

A pastagem é outra tipologia de uso da terra que interage com o meio ambiente sobretudo pela demanda de água para dessedentação e como fonte de alimentação extraída do solo. Os impactos ambientais mais recorrentes desse uso do solo são: eliminação ou redução da fauna e flora nativas como consequência do desmatamento; riscos de contaminação das águas; e assoreamento dos recursos hídricos, entre outros (JUCHEM, 1993).

A redução da pluviosidade na Amazônia e regiões vizinhas é um dos maiores problemas da conversão significativa de florestas para pastagens (FEARNSIDE, 1997), por isso a necessidade de manter o equilíbrio desse uso da terra com ecossistemas naturais em áreas de ocupação humana consolidada e naquelas onde há expansão da fronteira agropecuária. Contudo, os efeitos da pecuária dependem do tipo da espécie e do porte do animal (JUCHEM, 1993). Fearnside (2006) reitera que grande parte do desmatamento na Amazônia é realizada por grandes fazendeiros e a maioria das pastagens são pouco produtivas. O desmatamento acelerado na Amazônia tem reduzido a biodiversidade, alterado o ciclo da água e dificultado a absorção de dióxido de carbono (FEARNSIDE, 1997).

Santos (2008) reitera que o meio ambiente vem sendo cada vez mais artificializado e sua substituição ocorre por uma esfera técnica, tanto no campo, quanto na cidade. Assim, o índice de hemerobia tende a aumentar conforme os usos antrópicos sejam ampliados. Nesse sentido, as técnicas e as máquinas têm proporcionado à sociedade intervir no ambiente natural de maneira mais abrupta em extensão geográfica ao longo do tempo. 


\section{RESULTADOS E DISCUSSÃO}

No período analisado, o processo de urbanização ocorreu de modo desigual na Região Geográfica Imediata de Belém/PA. Os municípios de Belém, Ananindeua, Marituba e Benevides foram aqueles com maior crescimento da área urbana desde a década de 1980 em contraposição aos demais (Figura 4). A partir dos anos 1980, os eixos ao longo das rodovias BR-316 e da Augusto Montenegro tornaram-se os novos espaços de assentamentos urbanos, o que repercutiu em intensas mudanças de uso e cobertura da terra, com áreas pastoris e de floresta sendo convertidas para urbanas.

Figura 4 - Área Urbana dos municípios da Região Geográfica Imediata de Belém/PA

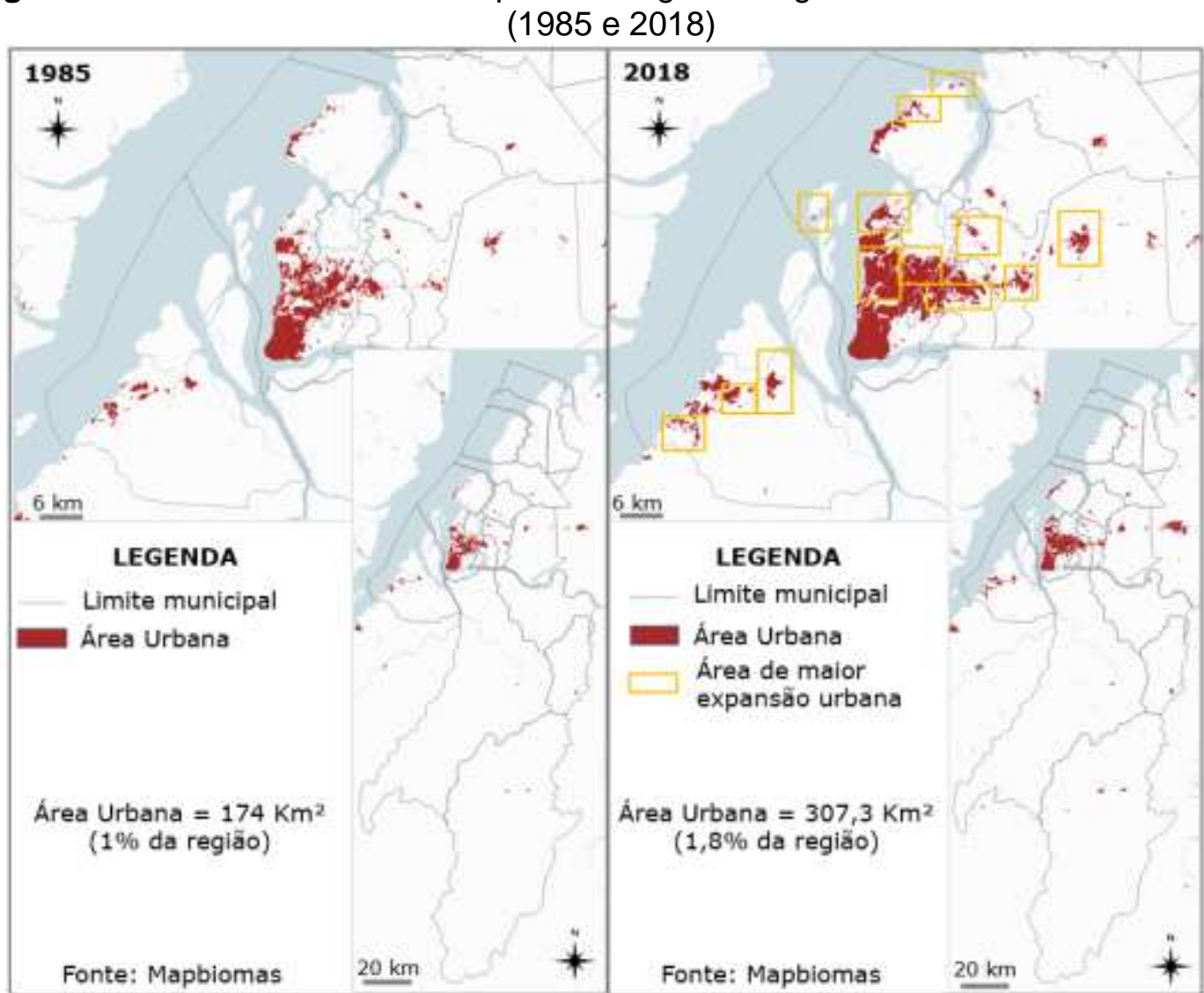

Fonte: MapBiomas (2020b).

De acordo com a Figura 4, as mudanças mais radicais sobre o ambiente natural no período ocorreram no norte de Belém (ao longo da rodovia Augusto Montenegro, do distrito de Outeiro, do distrito de Mosqueiro e parte da ilha de Cotijuba); em Ananindeua (bairro da Cidade Nova, do Curuçambá, do Icuí, do Paar e outros na porção sul); em Marituba (ao longo da rodovia BR-316 e da estrada do Decouville); em Benevides (arredores do centro da cidade e do distrito de Benfica); e nas adjacências do centro de Santa Izabel do Pará e de Barcarena. 
O crescimento urbano de Belém, segunda cidade mais populosa da Amazônia brasileira e polo da região metropolitana, é resultado do maior dinamismo e diversidade econômica, sobretudo no setor terciário desde a sua fundação em 1616. Ao longo dos séculos, a cidade cresceu ao longo da orla fluvial, se expandiu em direção ao interior da península (MOREIRA, 1966) até alcançar o estágio de metropolização que se iniciou na década de 1960 com incorporação de cidades e vilas em uma malha urbana única, apesar de fragmentada (TRINDADE JÚNIOR, 1998), visto com clareza na Figura 4.

O uso dos dados do MapBiomas permitiu a elaboração da Tabela 1 que destaca a pequena extensão territorial da área urbana na Região Geográfica Imediata de Belém, apesar do aumento no período analisado. A área urbana passou de 1\% em 1985 para 1,8\% em 2018. Entretanto, vale destacar, que parte significativa da área total dos municípios tratase da malha fluvial, portanto, não urbanizável para os padrões vigentes na região.

Ainda de acordo com a Tabela 1 e a Figura 4, é visível que as áreas urbanas eram quase inexpressivas em vários municípios como: Acará $(0,1 \%)$; São Caetano de Odivelas, Bujaru, Colares e Tomé-Açu (0,2\%); Concórdia do Pará $(0,5 \%)$ e Vigia $(0,8 \%)$ para o ano de 2018 (MAPBIOMAS, 2020b). Portanto, a extensão dos impactos ambientais nítidos das áreas urbanas, nesse período, é menos expressiva nesses municípios.

Tabela 1 - Área urbana dos municípios da Região Geográfica Imediata de Belém/PA

\begin{tabular}{c|c|c|c|c|c}
\hline \multirow{2}{*}{ Município } & \multicolumn{2}{|c}{$\begin{array}{c}\text { Área Urbana } \\
\text { (área total) }\end{array}$} & \multicolumn{3}{c}{$\%$ do total do município } \\
\cline { 2 - 6 } & $1985\left(\mathrm{~km}^{2}\right)$ & $2018\left(\mathrm{~km}^{2}\right)$ & $1985(\%)$ & $2018(\%)$ & Variação \% \\
\hline Belém & 98,8 & 140,4 & 9,3 & 13,2 & $+42,1$ \\
\hline Ananindeua & 32,8 & 58,2 & 17,2 & 30,5 & $+77,4$ \\
\hline Marituba & 7,8 & 20,3 & 7,5 & 19,7 & $+160,3$ \\
\hline Benevides & 4,7 & 13,9 & 2,5 & 7,4 & $+195,7$ \\
\hline Barcarena & 14,5 & 32,1 & 1,1 & 2,5 & $+121,4$ \\
\hline Bujaru & 0,6 & 2 & 0,1 & 0,2 & $+233,3$ \\
\hline Santa Bárbara do Pará & 1,7 & 2,7 & 0,6 & 1 & $+58,8$ \\
\hline Santa Izabel do Pará & 4,7 & 12,2 & 0,7 & 1,7 & $+159,6$ \\
\hline São Caetano de Odivelas & 0,7 & 1,8 & 0,1 & 0,2 & $+157,1$ \\
\hline Colares & 0,5 & 1,3 & 0,1 & 0,2 & +160 \\
\hline Vigia & 1,4 & 4,1 & 0,3 & 0,8 & $+192,9$ \\
\hline Acará & 0,7 & 2,5 & $<0,1$ & 0,1 & $+257,1$ \\
\hline Concórdia do Pará & 1,7 & 3,3 & 0,2 & 0,5 & $+94,1$ \\
\hline Tomé-Açu & 2,1 & 8,6 & $<0,1$ & 0,2 & $+309,5$ \\
\hline TOTAL & 174 & 307,3 & 1 & 1,8 & $+76,6$ \\
\hline Fonte: & 1,4 & 4 & 0,3 & 0,7 & $+185,7$ \\
\hline
\end{tabular}

Fonte: MapBiomas (2020b). 
Soares Mendes (2019) afirma que as áreas urbanizadas de Ananindeua e Marituba expandiram com maior força em decorrência de conjuntos habitacionais e ocupações espontâneas. Esses processos também ocorreram de maneira acentuada em Belém e Benevides. No período analisado, a área urbana cresceu 133,3 quilômetros quadrados na área de estudo. Essa classe era mais representativa em municípios metropolitanos do que nos não-metropolitanos. Depreende-se daí que as alterações nas dinâmicas naturais se tornaram mais intensas à medida que as cidades cresceram na área de estudo.

A extensão mais limitada de áreas urbanas em municípios não-metropolitanos está em consonância com outro uso do solo mais frequente, a pastagem. As pastagens são concebidas como áreas predominantemente plantadas, vinculadas a atividade agropecuária (MAPBIOMAS, 2020a). Essa tipologia foi a principal responsável por impactos ambientais nos ecossistemas da maioria dos municípios estudados, já que a sua extensão territorial era maior do que áreas urbanas. A expansão das pastagens ocorreu sobretudo no nordeste, leste e sul da região, como se pode constatar ao visualizar os mapas construídos com as informações de cobertura vegetal coletadas no site do MapBiomas para os anos de 1985 e 2018 (Figura 5).

Figura 5 - Área de pastagem dos municípios da Região Geográfica Imediata de Belém/PA (1985 e 2018)

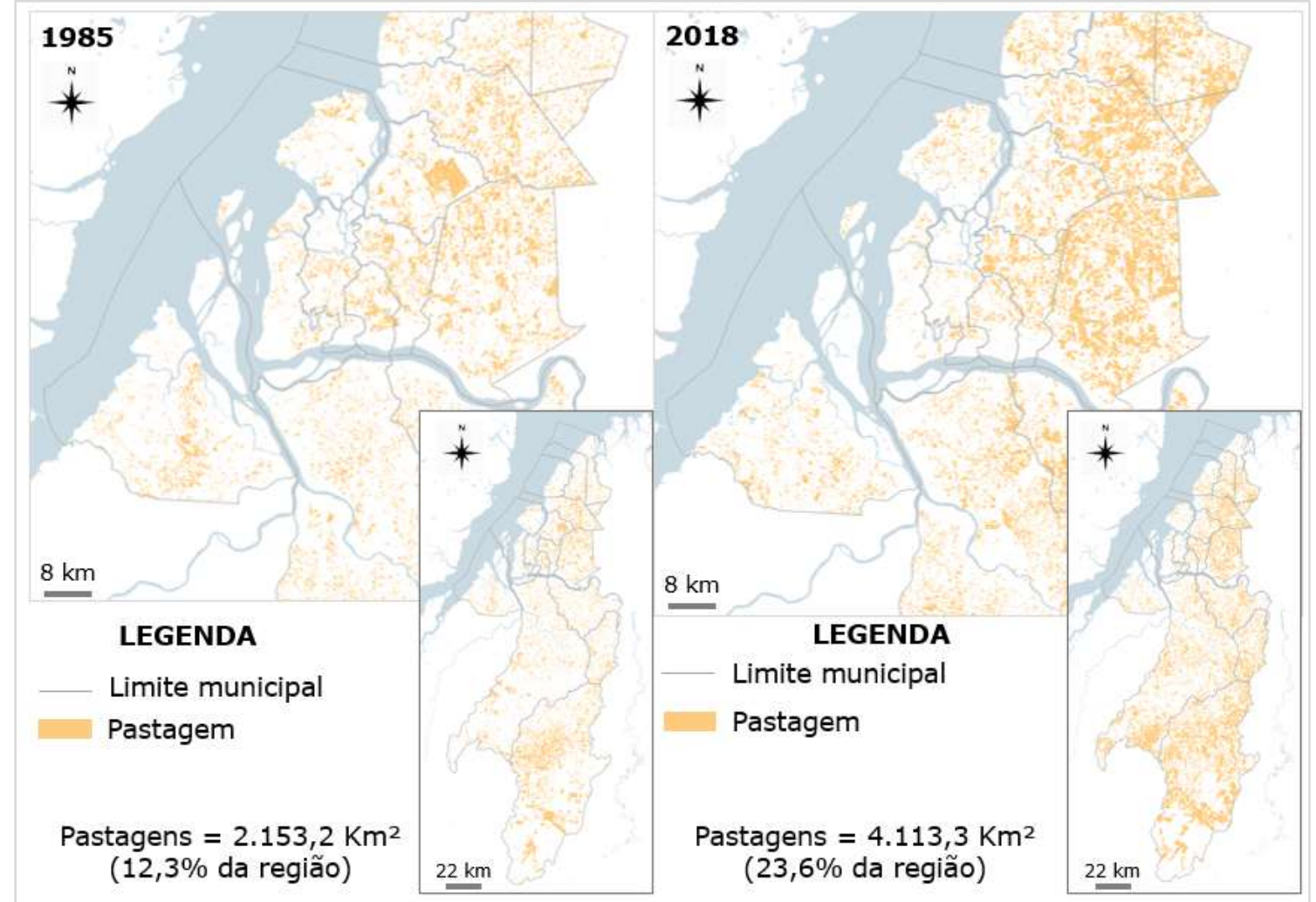

Fonte: MapBiomas (2020b). 
A pecuária é uma atividade de grande rentabilidade e atratividade de investimentos na Amazônia, dado o valor da terra (CASTRO, 2005), inclusive em locais relativamente próximos aos centros urbanos. Essa é uma das explicações para a expansão significativa das pastagens na área de estudo (1.960,1 quilômetros quadrados), principalmente no município de Acará (149,4\%), São Caetano de Odivelas (145,5\%), Bujaru (141,2\%) e em Concórdia do Pará (123,7\%) no período analisado.

No ano de 2018, as pastagens ocupavam grandes extensões de terra nos municípios de Santa Izabel do Pará $(38,4 \%)$, Concórdia do Pará (34,3\%), Tomé-Açu (33,3\%) e Santo Antônio do Tauá (31,7\%), conforme evidencia a Tabela 2. No sentido oposto, Ananindeua, Marituba e Santa Bárbara do Pará tiveram redução em suas áreas de pastagens face, inclusive, a pressão da urbanização sobre terras rurais, o que eleva o preço do solo tornando pouco rentável seu uso para fins agropastoris. Já em Belém - sobretudo na região insular mais distante do núcleo principal -, e em Barcarena houve um pequeno crescimento da classe em suas áreas rurais.

Tabela 2 - Área de pastagem dos municípios da Região Geográfica Imediata de Belém/PA (1985 e 2018)

\begin{tabular}{c|c|c|c|c|c}
\hline \multirow{2}{*}{ Município } & \multicolumn{3}{|c|}{$\begin{array}{c}\text { Pastagens } \\
(\text { área total) }\end{array}$} & \multicolumn{3}{c}{ do total do município } \\
\cline { 2 - 6 } & $1985\left(\mathrm{~km}^{2}\right)$ & $2018\left(\mathrm{~km}^{2}\right)$ & $1985(\%)$ & $2018(\%)$ & Variação \% \\
\hline Belém & 34,9 & 36,8 & 3,3 & 3,5 & $+5,4$ \\
\hline Ananindeua & 15,6 & 10 & 8,2 & 5,3 & $-35,9$ \\
\hline Marituba & 19,7 & 13,2 & 19 & 12,8 & -33 \\
\hline Benevides & 36,9 & 52,5 & 19,6 & 27,9 & $+42,3$ \\
\hline Barcarena & 62,2 & 66,7 & 4,7 & 5,1 & $+7,2$ \\
\hline Bujaru & 101,9 & 245,8 & 10,1 & 24,5 & $+141,2$ \\
\hline Santa Bárbara do Pará & 57,3 & 53,1 & 20,6 & 19,1 & $-7,3$ \\
\hline Santo Antônio do Tauá & 158,2 & 275,5 & 22 & 38,4 & $+74,1$ \\
\hline São Caetano de Odivelas & 102,2 & 170,5 & 19 & 31,7 & $+66,8$ \\
\hline Colares & 20,2 & 34,7 & 3,3 & 5,7 & $+71,8$ \\
\hline Vigia & 52,7 & 109,6 & 9,8 & 20,3 & +108 \\
\hline Acará & 398,3 & 993,3 & 9,2 & 22,9 & $+149,4$ \\
\hline Concórdia do Pará & 105,9 & 236,9 & 15,3 & 34,3 & $+123,7$ \\
\hline Tomé-Açu & 946,3 & $1.713,7$ & 18,4 & 33,3 & $+81,1$ \\
\hline TOTAL & $2.153,2$ & $4.113,3$ & 12,3 & 23,6 & +91 \\
\hline Fonte: & & & & & \\
\hline MapBiomas $(2020 b)$ & 100,9 & 5,5 & 13,6 & $+145,5$ \\
\hline & & & & \\
\hline
\end{tabular}

Fonte: MapBiomas (2020b).

Em toda região, o avanço das pastagens foi de $91 \%$, maior do que o crescimento de áreas urbanas (76,6\%) no período (MAPBIOMAS, 2020b). A extensão territorial das pastagens (4.113,3 quilômetros quadrados) era 13,3 maior do que as áreas urbanizadas 
(307,3 quilômetros quadrados) no ano de 2018. Em outras palavras, as pastagens têm descaracterizado muito mais o ambiente natural da Região Geográfica Imediata de Belém do que as áreas urbanizadas.

A análise desses dados permite afirmar que diversas classes predominantemente naturais da região como florestas, mangues, apicuns e outras formações vegetais foram substituídas, majoritariamente, por espaços diretamente manejados pelas sociedades, como pastos e áreas urbanas. O primeiro uso está atrelado principalmente à produção de carne e de leite, ao passo que o segundo é voltado à habitação, ao tráfego de veículos, à indústria, e à atividade comercial e de serviços.

Em pouco mais de três décadas, a região perdeu 2.325,5 quilômetros quadrados de ambientes naturais, quase $18 \%$ do total, o que é muito expressivo. Entre os municípios que sofreram as maiores reduções, destacam-se Concórdia do Pará (-4,7\%), Santa Izabel do Pará (-24,1\%), Santo Antônio do Tauá (-21,8\%) e Tomé-Açu (-20,9\%), conforme pode ser visto Tabela 3. A partir da Tabela 3 percebe-se que os municípios onde o crescimento absoluto de áreas urbanas foi maior (Belém, Ananindeua, Marituba e Barcarena) não foram aqueles com as maiores reduções de áreas predominantemente naturais em decorrência do processo de adensamento populacional próximo aos centros urbanos.

No caso de Belém, também se destaca o processo de verticalização com número significativo de domicílios particulares enquadrados como apartamentos, sobretudo nos bairros centrais (GUSMÃO e SOARES, 2018). Ainda conforme a Tabela 3 e a Figura 6 é possível notar que as áreas de vegetação nativa, de praias e de dunas (quando presentes), ainda eram predominantes ou representativas em muitos municípios no ano de 2018, como em: Santa Bárbara do Pará (73,9\%), Bujaru (69,3\%), Tomé-Açu (64,4\%), Concórdia do Pará (63,6\%), Benevides (60,5\%), Santa Izabel do Pará (56,7\%) e Ananindeua (54,3\%), entre outros.

A Figura 6 enfatiza que perdas mais acentuadas de ambientes naturais coincidem com áreas onde as pastagens mais se expandiram, com destaque para o sul, nordeste e leste da região. As florestas e outras coberturas vegetais, próximas dos centros urbanos e de pastagens são ameaçadas por outros processos que não alteram significativamente as suas estruturas - a ponto de não ser detectável em imagens de satélite - como extração ilegal de madeira e queimadas em pequenas proporções e diversos tipos de poluição, entre outros.

Apesar do avanço das áreas urbanas e de pastagens ao longo de 33 anos analisados, as florestas ainda prevaleciam em 2018 na Região Geográfica Imediata de Belém, ao ocupar 59,6\% do território (Tabela 4). A área florestal na região em 2018 era cerca de 2,5 vezes maior que a extensão das pastagens e 33,8 vezes maior do que as áreas urbanas. Contudo, as florestas passaram de $73 \%$ no ano de 1985 para 59,6\% em 2018. Ademais, no 
ano de 2018 , os usos antrópicos mais representativos eram: pastagens $(23,6 \%)$ e áreas urbanizadas $(1,8 \%)$.

Tabela 3 - Classes predominantemente naturais dos municípios da Região Geográfica Imediata de Belém/PA (1985 e 2018)

\begin{tabular}{c|c|c|c|c|c}
\hline \multirow{2}{*}{ Município } & \multicolumn{2}{|c}{$\begin{array}{c}\text { Classes } \\
\text { predominantemente } \\
\text { naturais } \\
\text { (área total) }\end{array}$} & \multicolumn{3}{l}{} \\
\cline { 2 - 6 } & $1985\left(\mathrm{~km}^{2}\right)$ & $2018\left(\mathrm{~km}^{2}\right)$ & $1985(\%)$ & $2018(\%)$ & Variação \% \\
\hline Belém & 365,6 & 318,4 & 34,5 & 30 & $-12,9$ \\
\hline Ananindeua & 124 & 103,3 & 65,1 & 54,3 & $-16,7$ \\
\hline Marituba & 69,3 & 63,0 & 67,1 & 61 & $-9,1$ \\
\hline Benevides & 139,5 & 113,7 & 74,2 & 60,5 & $-18,5$ \\
\hline Barcarena & 719,7 & 693,4 & 54,9 & 52,9 & $-3,7$ \\
\hline Bujaru & 844 & 694,4 & 84 & 69,3 & $-17,5$ \\
\hline Santa Bárbara do Pará & 204,5 & 205,5 & 73,5 & 73,9 & $+0,5$ \\
\hline Santo Antônio do Tauá & 344,1 & 269,2 & 64 & 50,1 & $-21,8$ \\
\hline São Caetano de Odivelas & 401,4 & 330,4 & 54 & 44,4 & $-17,7$ \\
\hline Colares & 226,5 & 203,9 & 37,1 & 33,4 & -10 \\
\hline Vigia & 337,7 & 271,6 & 62,6 & 50,4 & $-19,6$ \\
\hline Acará & $3.887,5$ & $3.216,5$ & 89,5 & 74 & $-17,3$ \\
\hline Concórdia do Pará & 583,3 & 439,1 & 84,4 & 63,6 & $-24,7$ \\
\hline Tomé-Açu & $4.188,4$ & $3.314,6$ & 81,4 & 64,4 & $-20,9$ \\
\hline TOTAL & $12.971,5$ & 10.646 & 74,3 & 61 & $-17,9$ \\
\hline
\end{tabular}

Fonte: MapBiomas (2020b).

As maiores reduções de áreas nativas foram verificadas nas classes apicum (-73,33\%) e florestas (-18,28\%). Já aquelas classes com os maiores acréscimos foram: floresta plantada $(+2.700 \%)$, pastagens $(+91 \%)$ e áreas urbanas $(+76,6 \%)$. Assim, a Região Geográfica Imediata de Belém foi classificada predominantemente como Mesohemeróbica (moderadamente modificada) tanto em 1985 quanto em 2018 (Figura 7), ainda que as florestas naturais sejam preponderantes. Os índices hemerobióticos da área de estudo foram de 2,18 em 1985 e 2,30 em 2018, com aumento de 5,5\% na região como um todo. As classes de maior transformação do ambiente natural, poli-euhemeróbico e metahemeróbico, eram pouco representativas na área estudo, ocupavam apenas $1 \%$ do território em 1985 e 2,8\% em 2018, caso a hidrografia seja considerada.

Outra razão que explica os menores índices hemerobióticos da região é a abundância de água (Figura 8) como rios e baías nos limites territoriais. Isto inevitavelmente contribuiu para que o crescimento de áreas urbanas e de pastagens fosse menos perceptível no índice 
final, sobretudo nos municípios com maior extensão da água nos limites territoriais, como: Belém, Barcarena, Colares, São Caetano de Odivelas, Santo Antônio do Tauá e Vigia.

Figura 6 - Áreas predominantemente naturais, pastagens, áreas urbanizadas e outros usos antrópicos da Região Geográfica Imediata de Belém/PA (1985 e 2018)

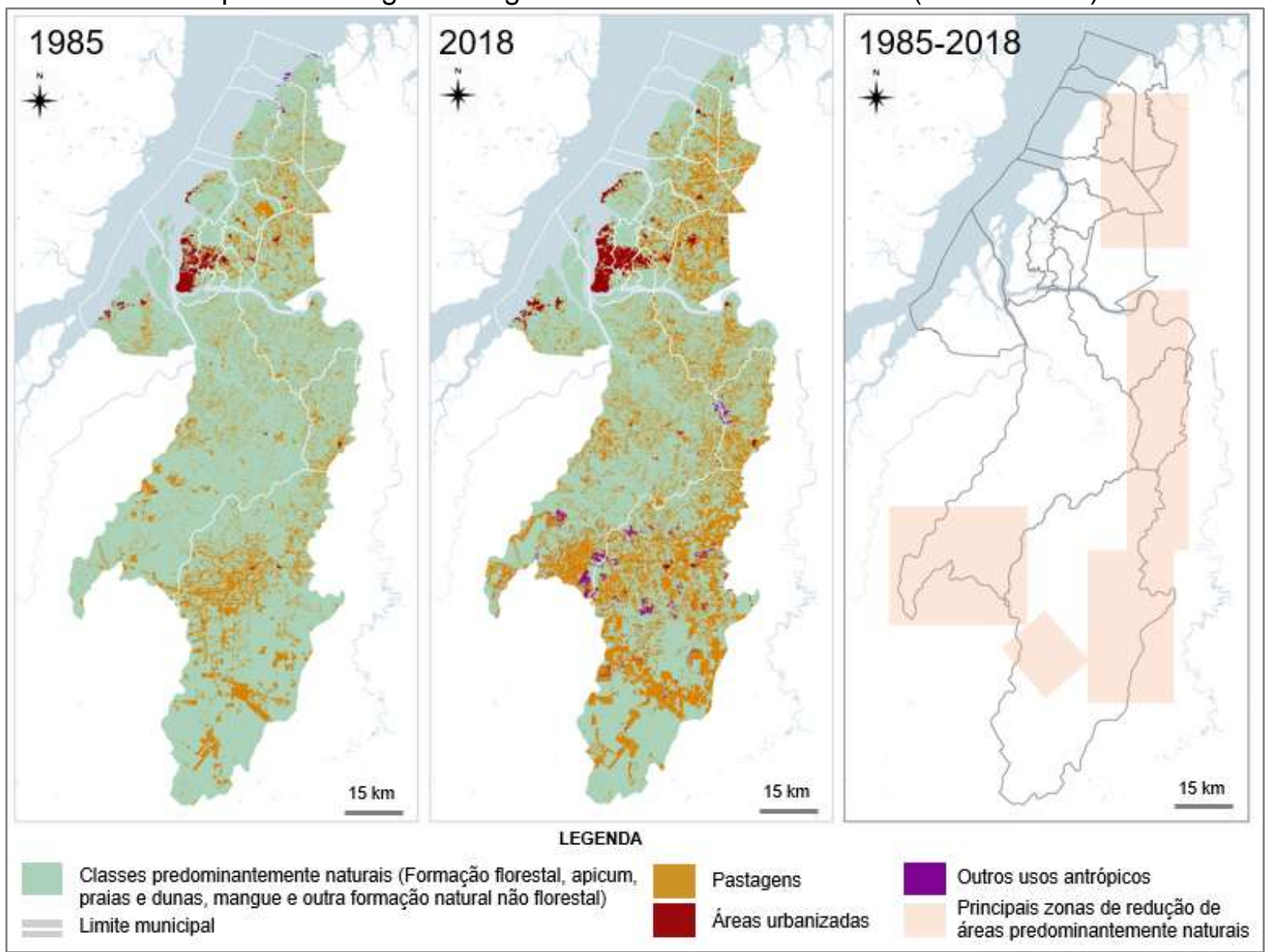

Fonte: MapBiomas (2020b).

A Figura 8 retrata a diversidade da predominância de uso manejado nos municípios da região. Em 12 deles (80\%), a pastagem é o uso da terra mais extenso de todos. Em apenas três municípios (Belém, Ananindeua e Marituba), a área urbana é maior que a área de pastagem. As mudanças ambientais impostas pela pecuária extensiva, sobretudo a do gado bovino, é representativa na maior parte da Amazônia Legal (MELLO e THERY, 2001), assim como na maioria dos municípios da área de estudo. A expansão da pecuária foi uma das principais causas de desmatamento na Amazônia (CASTRO, 2005; MELLO e THERY, 2001), principalmente entre a década de 1970 e de 1990 (MELLO e THERY, 2001), cujo resultado foi também constatado no presente estudo.

O avanço do uso da terra contribuiu para o aumento do índice hemerobiótico dos municípios estudados. No entanto, a classe de hemerobia da maioria não foi alterada (Figura 9), cujo enquadramento permaneceu Mesohemeróbico (moderadamente alterada), apesar dos padrões de uso e cobertura da terra serem heterogêneos. Conforme a Figura 9 , 
as maiores variações do índice foram no sul e leste da região. Os municípios de Ananindeua $(+21,8 \%)$ e Marituba $(+21,3 \%)$ foram aqueles com as maiores mudanças nas paisagens durante o período. Foram os únicos da região na categoria beta-euhemeróbicos, ou seja, mais que moderadamente transformados

Tabela 4 - Áreas das classes de uso ou cobertura da terra da Região Geográfica Imediata de Belém/PA (1985 e 2018)

\begin{tabular}{c|c|c|c|c|c}
\hline Município & $1985\left(\mathrm{~km}^{2}\right)$ & $2018\left(\mathrm{~km}^{2}\right)$ & $1985(\%)$ & $2018(\%)$ & Variação \% \\
\hline Formação Florestal & $12.739,9$ & $10.411,6$ & 73 & 59,6 & $-18,3$ \\
\hline Mangue & 161,7 & 167,5 & 0,9 & 1 & $+3,6$ \\
\hline Pastagem & $2.153,2$ & $4.113,3$ & 12,3 & 23,6 & +91 \\
\hline Infraestrutura Urbana & 174 & 307,3 & 1 & 1,8 & $+76,6$ \\
\hline Agricultura & 0 & 165,9 & 0 & 1 & $\mathrm{X}$ \\
\hline Corpo d'água & $2.162,9$ & $2.202,1$ & 12,4 & 12,6 & $+1,8$ \\
\hline Apicum & 1,5 & 0,4 & $<0,1$ & $<0,1$ & $-73,3$ \\
\hline Praia e Duna & 0,2 & 0,2 & $<0,1$ & $<0,1$ & $\mathrm{X}$ \\
\hline Floresta Plantada & 1 & 28 & $<0,1$ & 0,2 & +2.700 \\
\hline O. formação não florestal & 47,2 & 65,1 & 0,3 & 0,4 & $+37,9$ \\
\hline O. áreas não vegetadas & 20,9 & 1,1 & 0,1 & $<0,1$ & $-81,9$ \\
\hline Mineração & $<0,1$ & $<0,1$ & $<0,1$ & $<0,1$ & $\mathrm{X}$ \\
\hline TOTAL & $17.462,6$ & $17.462,6$ & 100 & 100 & $\mathrm{X}$ \\
\hline
\end{tabular}

Fonte: MapBiomas (2020b).

Figura 7 - Área da Região Geográfica Imediata de Belém conforme a classificação hemerobiótica para o ano de 1985 e 2018

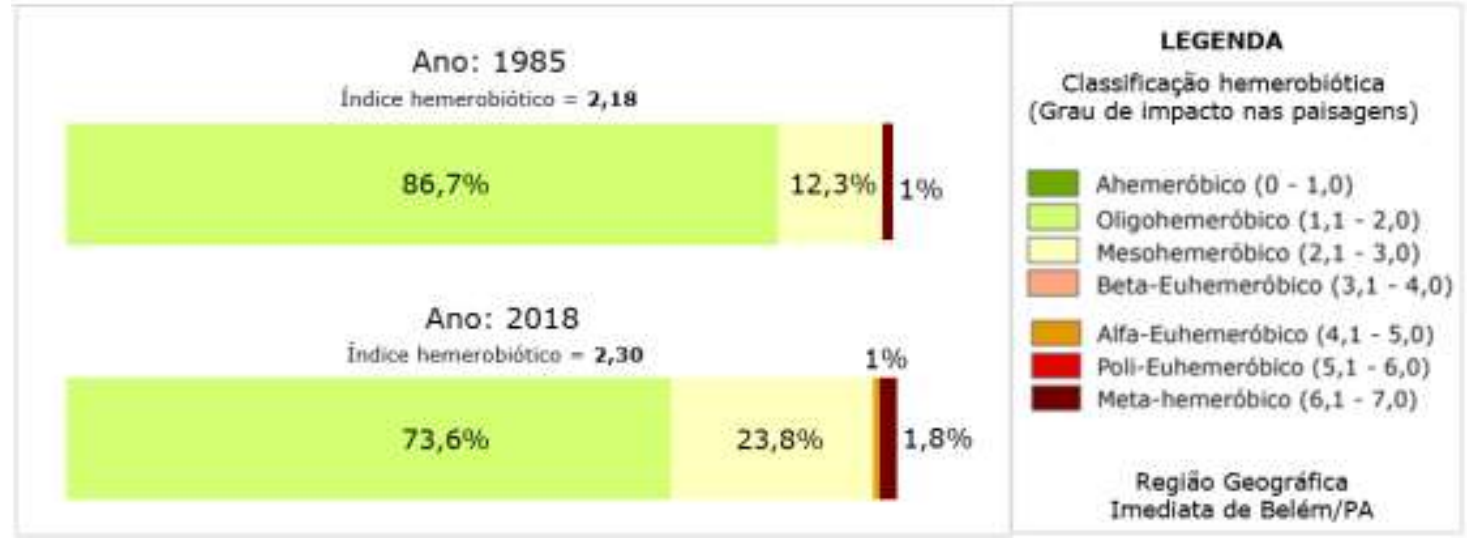

Fonte: MapBiomas (2020a).

Os municípios de Concórdia do Pará, Acará, Santa Izabel do Pará e Benevides tiveram aumento considerado alto no grupo, entre 8,8\% e 14,7\%. Já Belém, Santo Antônio do Tauá, Bujaru e Vigia registraram aumento moderado do índice, entre 6,3\% e 8\%. Por fim, no restante deles, com exceção de Colares, a mudança foi baixa, entre $0,4 \%$ e $4,4 \%$. 
Figura 8 - Classes de uso e cobertura da terra dos municípios da área de estudo (2018)

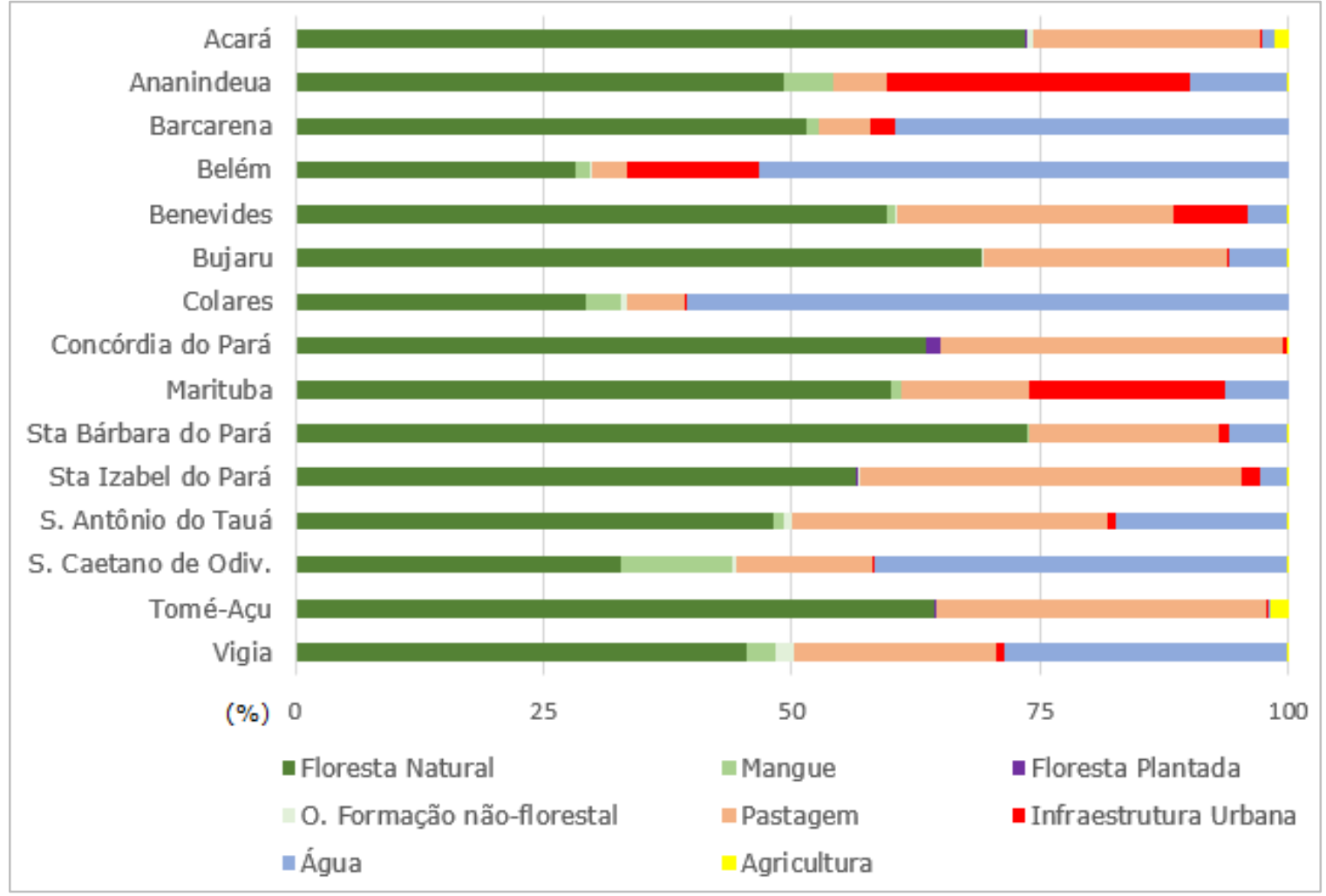

Fonte: MapBiomas (2020b). 
Figura 9 - Grau de impacto humano nas paisagens e variação do índice hemerobiótico dos municípios da Região Geográfica Imediata de Belém/PA (1985 e 2018)

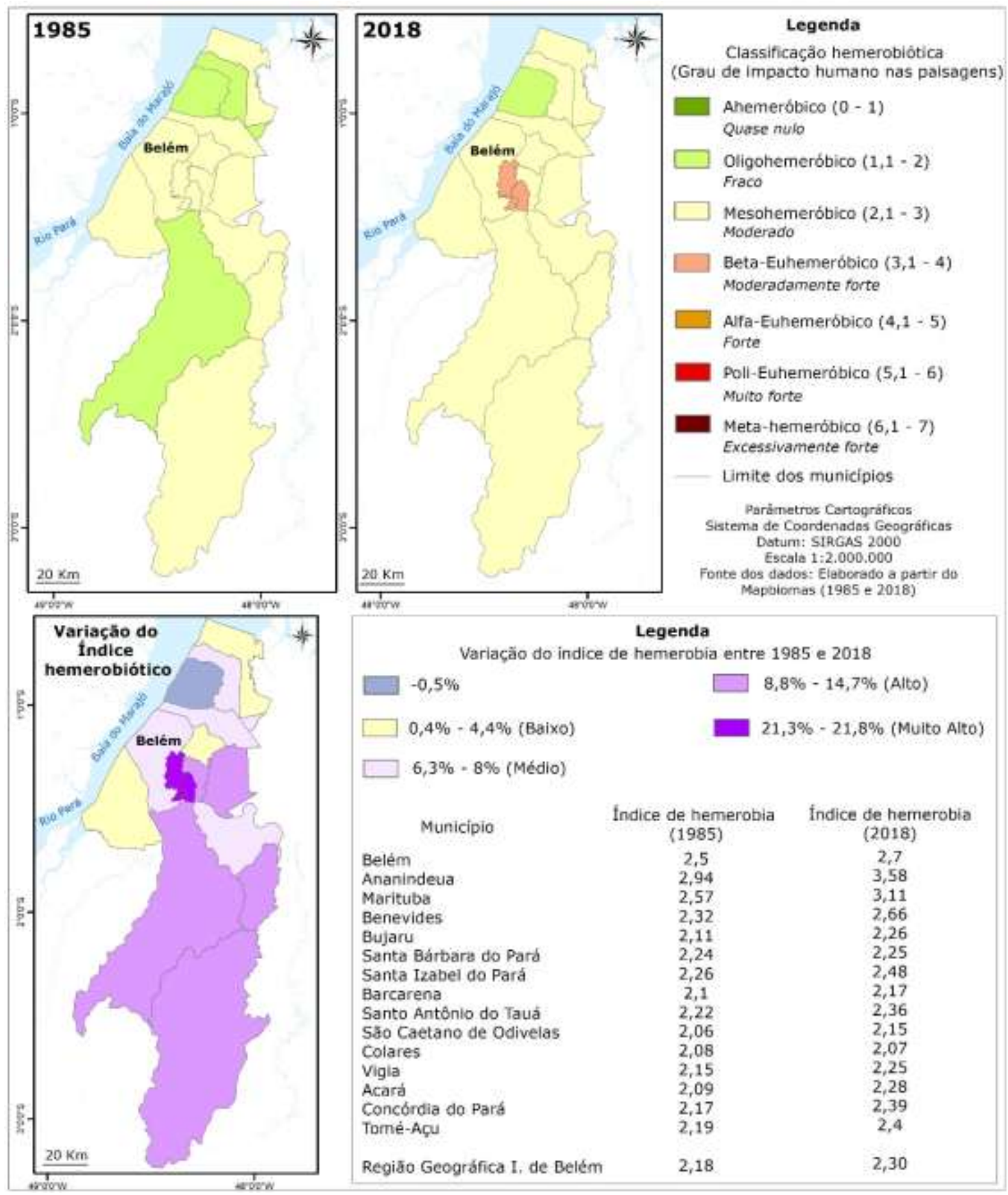

Fonte: MapBiomas (2020b).

\section{CONCLUSÕES E CONSIDERAÇÕES FINAIS}

As pastagens são as principais responsáveis pela degradação e alteração dos componentes naturais da Região Geográfica Imediata de Belém/PA, sobretudo nos municípios não metropolitanos. Pela expansão desse uso da terra, o tipo de manejo menos 
agressivo aos ecossistemas deve ser priorizado para minimizar a perda de biodiversidade e mudanças drásticas da paisagem natural.

Ficou evidente que a área urbana, classe de maior transformação da paisagem, cresceu significativamente ao longo das décadas sobretudo nos municípios da Região Metropolitana de Belém. Essa classe representou a segunda causa de conversão de ecossistemas naturais em uso antrópico. Todavia, cobre uma área restrita da área de estudo. Para as áreas urbanas são necessárias políticas de incentivo à redução do consumo de combustíveis fósseis, aumento de unidades de conservação ambiental, proteção dos mananciais, ocupação do espaço em consonância com vegetação nativa e outras práticas mais sustentáveis.

Os resultados destacaram que as florestas predominam na maior parte da Região Geográfica Imediata de Belém, apesar das expansões de áreas urbanizadas e de pastagens. A preservação das florestas é essencial para manter a biodiversidade, por isso a necessidade de adotar medidas que reduzam impactos ambientais significativos como: demarcação de unidades de preservação ambiental, desenvolvimento do ecoturismo, monitoramento do desmatamento, fiscalização rígida de propriedades rurais e fomento a outras atividades econômicas que as valorizem.

A maioria dos municípios da região foram classificados como mesohemeróbicos, ou seja, suas paisagens já foram moderadamente impactadas pelas atividades antrópicas. Assim, todos os municípios da região devem adotar políticas públicas que garantam o desenvolvimento socioeconômico sem alterações substanciais da paisagem, tal como medidas de mitigação para os impactos já realizados, sobretudo aqueles com os maiores índices de hemerobia.

Pode-se concluir que o conceito de hemerobia e suas classificações de alteração da paisagem são ferramentas importantes na análise da sustentabilidade ambiental, sobretudo pela avaliação do impacto da conversão de ambientes naturais em áreas antropizadas. Mas, evidencia também que a mera classificação em categorias hemerobióticas pode minimizar ou ocultar processos relevantes de alteração na paisagem. Considerando esses aspectos, a abordagem da hemerobia pode subsidiar o planejamento e contribuir de maneira substancial para o monitoramento ambiental em múltiplas escalas, bem como orientar a adoção de políticas públicas nesse âmbito.

\section{REFERÊNCIAS}

BELÉM, Anderson Luiz Godinho; NUCCI, João Carlos. Hemerobia das paisagens: conceito, classificação e aplicação no bairro de Pici - Fortaleza/CE. RAÉ GA, Curitiba, v. 21. p. 204233, 2011. Disponível em: https://revistas.ufpr.br/raega/article/view/21247/14031. Acesso em: 12 ago. 2020. 
BERTRAND, Georges. Paisagem e Geografia Física Global. Esboço Metodológico. RAÉ GA, Curitiba, n. 8, p. 141-152, 2004. Disponível em:

https://revistas.ufpr.br/raega/article/view/3389/2718. Acesso em:12 ago. 2020.

BERTO, Vagner Zamboni. Evolução e hemerobia da paisagem como indicadores de sustentabilidade ambiental urbana com base nos princípios do planejamento da paisagem: um estudo de caso do bairro Cachoeira no município de Curitiba-PR. Tese (Doutorado em Geografia), 2019. Disponível em:

https://acervodigital.ufpr.br/handle/1884/66132. Acesso em: 1 ago. 2020

CASTRO, Edna. Dinâmica socioeconômica e desmatamento na Amazônia. Novos

Cadernos NAEA, Belém, v. 8. p. 5-39, 2005. Disponível em:

http://repositorio.ufpa.br/jspui/bitstream/2011/3175/1/Artigo_DinamicaSocioeconomicaDesm atamento.pdf. Acesso em: 02 nov. 2020.

FEARNSIDE, Philip Martin. Serviços ambientais como estratégia para o desenvolvimento sustentável na Amazônia rural. 1997. Disponível em: http://philip.inpa.gov.br/publ_livres/2000/Serv\%20Ambientais\%20BSGI.pdf. Acesso em: 18 nov. 2020.

FEARNSIDE, Philip Martin. Desmatamento na Amazônia: dinâmica, impacto e controle.

Acta Amazônia. v. 36. n.3. p.395-400, 2006. Disponível em:

https://www.scielo.br/pdf/aa/v36n3/v36n3a18.pdf. Acesso em: 15 out. 2020.

GUSMÃO, Luiz Henrique Almeida; SOMBRA, Daniel Araújo. Produção desigual do espaço: o processo de verticalização em Belém (PA). Contribuciones a las Ciencias Sociales, v. 39, p.1-17, 2018. Disponível em:

https://www.researchgate.net/publication/322369694_PRODUCAO_DESIGUAL_DO_ESPA CO_O_PROCESSO_DE_VERTICALIZACAO_EM_BELEM_PA. Acesso em: 27 mar. 2021.

IBGE. INSTITUTO BRASILEIRO DE GEOGRAFIA E ESTATÍSTICA. Divisão Regional do Brasil em Regiões Geográficas Imediatas e Regiões Geográficas Intermediárias: 2017. IBGE. Coordenação de Geografia. - Rio de Janeiro: IBGE, 2017. Disponível em: https://www.ibge.gov.br/apps/regioes_geograficas//. Acesso em: 30 set. 2020.

IBGE. INSTITUTO BRASILEIRO DE GEOGRAFIA E ESTATÍSTICA. Estimativas da população 2020. 2020a. Disponível em:

https://www.ibge.gov.br/estatisticas/sociais/populacao/9103-estimativas-depopulacao.html?=\&t=resultados. Acesso em: 30 set. 2020.

IBGE. INSTITUTO BRASILEIRO DE GEOGRAFIA E ESTATÍSTICA. Malha Municipal da Divisão Político Administrativa do Brasil. 2020b. Disponível em: https://www.ibge.gov.br/geociencias/organizacao-do-territorio/15774-

malhas.html?=\&t=downloads. Acesso em: 30 set. 2020.

JUCHEM, Peno Ari. Técnicas para avaliação de impacto ambiental e elaboração de estudos de impacto ambiental de empreendimentos selecionados: projetos de aproveitamento hidrelétrico. Curitiba: SEMA/IAP/GTZ, 1993. Disponível em:

https://www.bdpa.cnptia.embrapa.br/consulta/busca?b=ad\&id=792163\&biblioteca=vazio\&bus ca=autoria:\%22JUCHEM,\%20P.\%20A.\%22\&qFacets=autoria:\%22JUCHEM,\%20P.\%20A.\% $22 \&$ sort=\&paginacao=t\&paginaAtual=1. Acesso em: 26 ago. 2020.

MAPBIOMAS. Uso e Cobertura do solo. 2020a. Disponível em: https://plataforma.brasil.mapbiomas.org/. Acesso em: 1 jul. 2020.

MAPBIOMAS. Coleções Mapbiomas. 2020b. Disponível em: https://mapbiomas.org/colecoes-mapbiomas-1?cama_set_language=pt-BR. Acesso em: 26 jul. 2020.

MARTINELLI, Marcelo. Mapas da Geografia e Cartografia Temática. São Paulo: Contexto, 2011. 
MATEO RODRIGUEZ, José Manuel; SILVA, Edson Vicente da; CAVALCANTI, Agostinho Paula Brito. Geoecologia das Paisagens: uma visão geossistêmica da análise ambiental. Fortaleza: UFC edições, 2017. Disponível em:

http://www.ppggeografia.ufc.br/images/documentos/043710J_MIOLO_Geoecologia.pdf. Acesso em: 30 jul. 2020.

MELLO, Neli Aparecida de; THÉRY, Hervé. A armadura do espaço amazônico: eixos e zoneamentos. ALCEU. v. 1. p.181-214, 2001. Disponível em: http://revistaalceuacervo.com.puc-rio.br/media/alceu_n2_Mello\%20e\%20Thery.pdf. Acesso em: 27.out. 2020.

MOTTER, Adriana Fátima Canova. Um olhar sobre o processo de transformação da paisagem na bacia do rio Santa Rosa, nordeste do Rio Grande do Sul, de 1915 até os dias atuais. Dissertação (Mestrado em Geografia), 2011. Disponível em: https://repositorio.ufsm.br/handle/1/9345?show=full. Acesso em: 28 out. 2020.

MOREIRA, Eidorfe. Belém e sua expressão geográfica. Belém: Imprensa Universitária/UFPA, 1966. Disponível em: https://livroaberto.ufpa.br/jspui/handle/prefix/88. Acesso em: 12 fev. 2020.

NUCCI, João Carlos; FÁVERO, Oriana Aparecida. Desenvolvimento Sustentável e Conservação da Natureza em Unidades de Conservação: O caso da Floresta Nacional de Ipanema (Iperó/SP). RAÉ GA, Curitiba, n. 7, p. 63-77, 2003. Disponível em: https://revistas.ufpr.br/raega/article/view/3352/2688. Acesso em: 30 jul. 2020.

SANTOS, Milton. A Natureza do Espaço: Técnica e Tempo, Razão e Emoção. São Paulo: Edusp, 2008.

STEINHARDT, Uta; HERZOG, Felix; LAUSCH, Angela; MULLER, E.; LEHMANN, Steffen. Hemeroby index for landscape monitoring and evaluation. In: PHKY, Yuri A.; HYATT, D. Eric; LENZ, Roman. J. (eds): Environmental Indices - System Analysis Approach. Oxford: EOLSS Publ., 1999. p. 237-254. Disponível em:

https://www.researchgate.net/publication/237201744_Hemeroby_index_for_landscape_moni toring_and_evaluation. Acesso em: 20 ago. 2020.

SOARES MENDES, Luiz Augusto. A Geografia-Histórica da região metropolitana de Belém. Revista Espacialidades, v. 14, n. 1, p. 10-39, 2019. Disponível em: https://periodicos.ufrn.br/espacialidades/article/view/17798. Acesso em: 18 ago. 2020.

TRINDADE JÚNIOR, Saint-Clair Cordeiro da. Assentamentos urbanos e reestruturação metropolitana: o caso de Belém. GEOUSP Espaço E Tempo (Online), 2(2), 39-52, 1998. Disponível em: https://www.revistas.usp.br/geousp/article/view/123318. Acesso em: 15.ago 2020 .

WALZ, Ulrich.; STEIN, Christian. Indicators of hemeroby for the monitoring of landscape in Germany. Journal for Nature Conservation, v. 22, p. 279-289, 2014. Disponível em: https://www2.ioer.de/recherche/pdf/2014_walz_hemeroby_manuscrpt.pdf. Acesso em: 10 ago.2020.

Recebido: dezembro de 2020. Aceito: abril de 2021. 